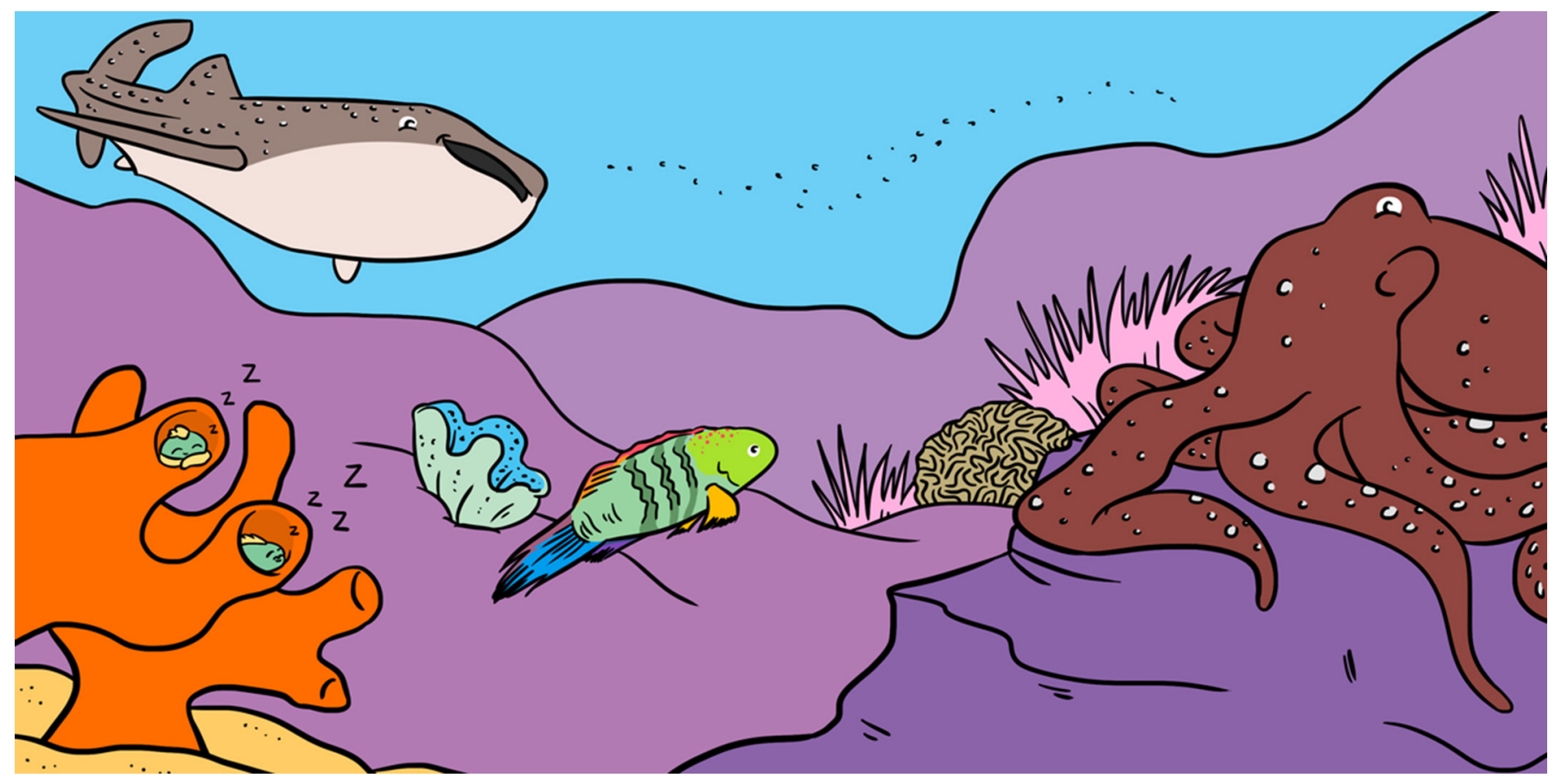

\title{
WHAT LIVES IN THE OCEAN? AN INTRODUCTION TO THE BIODIVERSITY OF THE RED SEA
}

\section{Marcelle M. Barreto *, Marcela Herrera and Manuel Aranda}

Biological and Environmental Science and Engineering Division/Red Sea Research Center, King Abdullah University of Science and Technology, Thuwal, Saudi Arabia

\section{YOUNG REVIEWER:}

FABIAN

AGE: 14
Have you ever wondered how many species are out there? Biodiversity refers to all the different plants and animals in the world, and it is incredibly important for our well-being. All organisms have a role in the environment, and healthy ecosystems depend on high biodiversity. For example, tiny plant-like organisms living in the ocean are responsible for most of the oxygen we breathe. Mangroves and coral reefs are homes for many wonderful fish, and they protect our coastlines from storms. The Red Sea is one of the world's most biodiverse oceans. It is a unique home to many different species that cannot be found anywhere else in the world. Scientists have estimated that there are around 29 species of sharks, 17 of whales and dolphins, 5 of marine turtles, 1,078 of fish, 359 of hard corals, and many more invertebrates. Imagine all the tiny microorganisms that we cannot see! 
Figure 1

Map of the Red Sea and its most important geographic features. Map tiles by Stemen Design, under CC BY 3.0. Data by OpenStreetMap, under CC BY SA.

\section{ADAPTATIONS}

Special characteristics of an organism that help the organism survive in its environment.

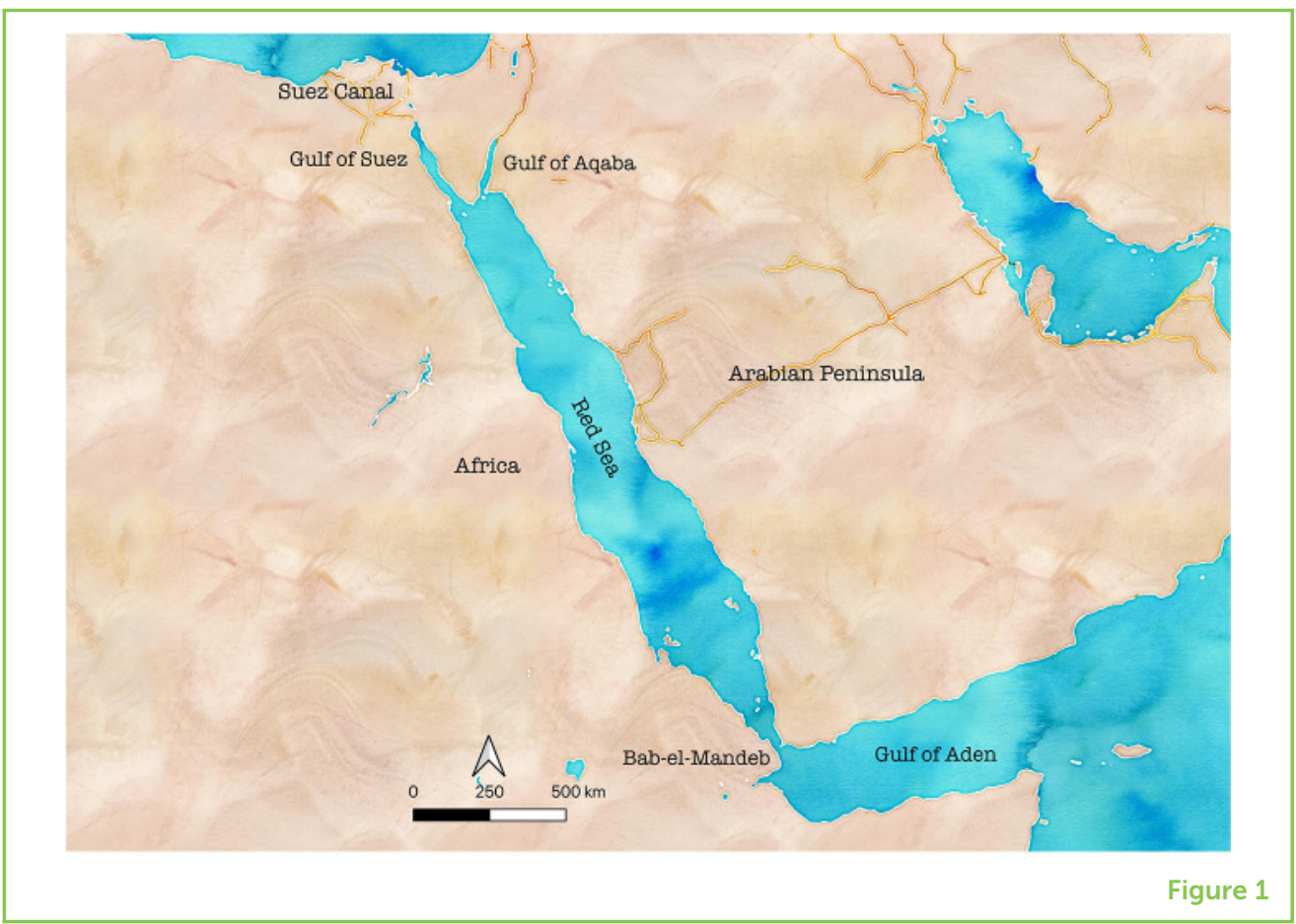

\section{THE RED SEA AND ITS UNIQUE BIODIVERSITY}

The Red Sea is a large body of water that separates Africa and Asia. It is connected to the Mediterranean Sea via the man-made Suez Canal, and to the Indian Ocean through a very narrow opening in the Gulf of Aden called Bab-el Mandeb (Figure 1). The Red Sea started forming due to a combination of events: the movement of the African and Arabian tectonic plates, and a change in sea level during a major ice age about 30 million years ago. The Red Sea became shallow and isolated and eventually limited the movement of animal and plants to the Indian Ocean. Unlike many seas, the Red Sea does not get water from rivers, so the water is very salty. It is actually one of the saltiest seas on Earth! It is also very warm, as the climate in this region of the world is extremely hot and sunny. Conditions in the nearby Indian Ocean are very different from those in the Red Sea, so species that came to the Red Sea needed specific adaptations to allow them to live there [1]. Because of this, the Red Sea has many species that can only be found in the Red Sea and nowhere else in the world!

\section{WHERE THE OCEAN MEETS THE LAND}

Just like we have forests on land, we also have trees and shrubs growing in the salty water near shore, in hot places like the Red Sea. These are called mangrove forests and they are very important because they protect the shore from big waves and are also home to many animals. Mangrove trees are different from other types of trees because they have special adaptations that allow them to live in the sea. Their roots have many pores to help them breathe, which is very 


\section{EROSION}

The process of removing soil, rock, and sediments by natural forces such as water flow or wind.

\section{ECOSYSTEM}

A community of many different organisms living together and interacting with their physical environment.

\section{INVERTEBRATES}

Animals that do not have backbones or internal skeletons.

\section{EXOSKELETONS}

External skeletons that support and protect the bodies of some invertebrate animals. important in their low-oxygen environment. They also have various ways to remove excess salt (Figure 2A). Some species of mangrove trees can expel more than $90 \%$ of the salt absorbed from the seawater! There are also other plants growing in the sea. Sea grasses live under water and provide shelter and food for organisms like turtles and sea cows. Sea grasses also have an important role in protecting the coast from erosion because their leaves soften the force of waves and help trap sediments such as sand or mud.

\section{A CORAL REEF WORLD}

Coral reefs (Figure 2B) are very special ecosystems that can only be found in certain areas of the world. Less than $1 \%$ of all the world's oceans are covered with coral reefs! The Red Sea contains one of the longest coral reef systems in the world, extending almost 2,000 km per side [2]. Coral reefs are primarily made of corals, which are actually colonies of tiny animals called polyps. Together with sea anemones and jellyfish, corals belong to a group of organisms called the Cnidaria. There are many different types of corals, but all can be grouped in one of two types: hard corals or soft corals. Hard corals, as the name suggests, have a hard skeleton, while soft corals do not. Corals can also have many different shapes and colors! Amongst the most abundant hard corals in the Red Sea is the brain coral (Figure 2C). Can you see why it has this name?

Coral reefs are home to many other sea creatures that are important for keeping reef communities in balance. Every animal has an important role in the reef ecosystem. Many of these animals are invertebrates, which means they do not have backbones or internal skeletons. Echinoderms, for example, live on the sea floor and cannot swim (Figure 2D). You have probably seen them: sea stars, sea urchins, sea cucumbers, feather stars, and brittle stars. All these animals are covered with tiny spines that protect them against predators, but even more fascinating is that they have something called radial symmetry. This means that you can divide their bodies into identical parts, like cutting a pizza into equal slices! Echinoderms protect reefs by eating algae and preventing them from growing over corals, which can harm corals by blocking the sunlight. In addition, some echinoderms live burrowed in the sand, so by moving around they help increase the amount of oxygen in the sediment, allowing other organisms to live there.

Well-known crustaceans can also be found in the Red Sea coral reef (Figure 2E). Have you ever seen crabs, shrimp, or lobsters before? These animals have exoskeletons, which are external skeletons that support and protect their bodies. One cool example of coral reef crustaceans is the pistol shrimp. These shrimps have large pincers, one larger than the other, with which they can produce a snapping sound. 


\section{Figure 2}

Biodiversity in the Red Sea. (A) Salt excretion under mangrove leaf. (B) Coral reef ecosystem. (C) Brain coral. (D)

Crown-of-thorns sea star. (E) Shrimp. (F) Marine sponge. (G) Giant clam. (H) Rusty parrotfish. (I) Whale shark. (J) Diatom, a type of plankton (Photo credits: A: Peripitus, Wikimedia commons; B-D: Marcelle Muniz Barreto; E,F,H: Morgan Benett-Smith; G: Susann Rossbach; I: Royale Hardenstine; $\mathbf{J}$ : Francisco Aparicio).

\section{SYMBIOTIC}

A close relationship in which both organisms benefit.

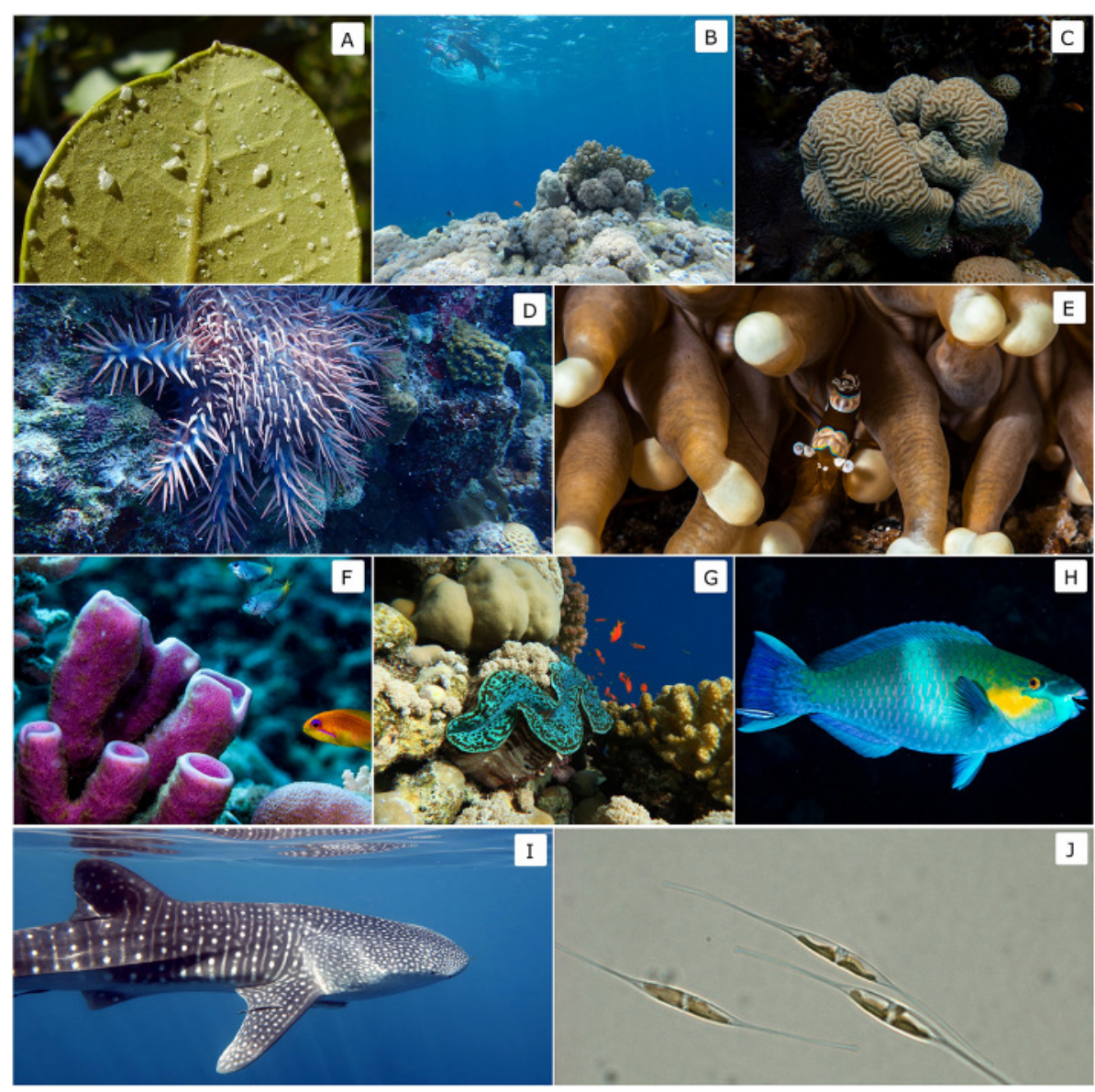

Figure 2

In fact, if you go snorkeling in the Red Sea, you will probably hear it! They use this pincer movement to stun their prey.

Some of the most abundant and funky animals in the Red Sea coral reef belong to the group Porifera, the sponges. Sponges are very simple animals that spend their entire lives attached to one place in the reef. Their bodies are full of pores, which are small openings through which they filter particles of food and oxygen from the water. Sponges come in many different shapes and colors. Because many are shaped like hollow tubes, they make good homes for tiny animals such as shrimp, worms, and fish (Figure 2F). You can see many fish sleeping inside sponges at night!

Animals like sea slugs, sea snails, bivalves such as clams and mussels, octopuses, and squids belong to the group Mollusca. They are soft-bodied but, in the case of bivalves, grow a hard shell to protect themselves. In the Red Sea coral reef, you can easily see a famous mollusk: the giant clam (Figure 2G). The bright blue tissue peeking out between the shells makes giant clams very easy to identify. These clams live in a symbiotic relationship with tiny algae, which generate energy from photosynthesis and give it to the clam. With this extra 
energy, giant clams can grow bigger than other clams. Another cool example is the mimic octopus, which can change its color to blend in with the surroundings and squirt out ink to distract predators. These octopuses can even grow back their arms if they lose them!

Unlike the invertebrates, fish have internal skeletons and backbonesthey are vertebrates. Fish also have gills that enable them to obtain oxygen from the water. All fish are important for coral reef health, because they have different functions. Red Sea plant eaters, like parrotfish (Figure $2 \mathrm{H}$ ) and surgeonfish, eat various types of algae and help keep them in check so they do not grow over corals. Meat eaters like groupers and sharks keep populations of smaller fish and other organisms in balance.

\section{FROM BIG TO SMALL}

Coral reefs contain only a part of the Red Sea's biodiversity. Many marine organisms live in the open ocean, ranging from microscopic plants to very big animals. Sharks, for example, are one of the oldest vertebrates on Earth. Scientists think the first sharks appeared more than 400 million years ago! In the Red Sea, there are 29 known shark species [3]. One of them is the whale shark (Figure 2I). The whale shark is actually the biggest fish in the world and can measure almost $20 \mathrm{~m}$, which is bigger than a city bus [4]! They have spots all over their bodies in patterns that are specific for each individual.

Marine mammals like whales and dolphins can also be found in the Red Sea. They belong to a group called Cetacea, which can be divided into two groups: baleen whales, which use the bristles in their mouths to filter prey from the water, and toothed whales, which use teeth to catch their prey. There are around 17 species of cetaceans in the Red Sea [5]. These animals can use echolocation-they use reflected sound waves to map their surroundings, allowing them to find prey and predators and to move around in the environment. Noise pollution from boat traffic or the oil industry can be dangerous to cetaceans because it can affect their ability to echolocate.

What about the organisms we cannot see? The ocean is full of organisms so tiny that you need a microscope to see them. They are called plankton. They are very diverse and abundant, with a single teaspoon of seawater containing thousands of them! Phytoplankton are a type of plankton that perform photosynthesis. They are essential for all marine life, because they are the basis of the marine food web. Phytoplankton are also responsible for much of the oxygen we breathe. Zooplankton are either tiny animals that live their whole lives as plankton (Figure 2J) or larvae, which are the young stages of other, bigger animals such as crustaceans, clams, and fish. Zooplankton perform the largest daily migration on the planet: during the day they are in deeper waters, protected from predators and excessive 
sunlight, and then they rise to the surface at night, where they can feed on phytoplankton.

As you can see, the Red Sea is full of life. Having many species is a very important quality because it helps an ecosystem to resist disturbances better and recover from them faster. And as you have learned, all the species in the Red Sea have their unique functions, which means we need as many species as we can to keep the Red Sea, and other oceans, healthy! That is why getting to know these species better and protecting them is essential, to guarantee the well-being of both ecosystems and people. There are a few things you can do to help the Red Sea and our oceans in general. Reducing use of single use plastics is one of them. Marine plastic pollution is a big problem for animals in the sea. They can mistake it for food and eat it, or get entangled in it. You can also ask the adults in your life to buy seafood that is sustainably farmed or caught. Just check for eco-labels and certifications! Can we count on you to help?

\section{REFERENCES}

1. DiBattista, J. D., Howard Choat, J., Gaither, M. R., Hobbs, J. P. A., Lozano-Cortés, D. F., Myers, R. F., et al. 2016. On the origin of endemic species in the Red Sea. J. Biogeogr. 43:13-30. doi: 10.1111/jbi.12631

2. Berumen, M. L., Hoey, A. S., Bass, W. H., Bouwmeester, J., Catania, D., Cochran, J. E. M., et al. 2013. The status of coral reef ecology research in the Red Sea. Coral Reefs 32:737-48. doi: 10.1007/s00338-013-1055-8

3. Spaet, J. L. Y. 2019. "Red sea sharks-biology, fisheries and conservation," in Oceanographic and Biological Aspects of the Red Sea, eds N. M. A. Rasul and I. C. F. Stewart (Cham: Springer International Publishing). p. 267-80.

4. Borrell, A., Aguilar, A., Gazo, M., Kumarran, R. P., and Cardona, L. 2011. Stable isotope profiles in whale shark (Rhincodon typus) suggest segregation and dissimilarities in the diet depending on sex and size. Environ. Biol. Fishes 92:559-67. doi: 10.1007/s10641-011-9879-y

5. Costa, M., Fumagalli, M., and Cesario, A. 2019. "Review of Cetaceans in the Red Sea," in Oceanographic and Biological Aspects of the Red Sea, eds N. M. A. Rasul and I. C. F. Stewart (Cham: Springer International Publishing). p. 281-303.

SUBMITTED: 10 June 2020; ACCEPTED: 14 September 2021; PUBLISHED ONLINE: 15 October 2021.

EDITED BY: Rúben Martins Costa, King Abdullah University of Science and Technology, Saudi Arabia

CITATION: Barreto MM, Herrera M and Aranda M (2021) What Lives in the Ocean? An Introduction to the Biodiversity of the Red Sea. Front. Young Minds 9:571379. doi: 10.3389/frym.2021.571379

CONFLICT OF INTEREST: The authors declare that the research was conducted in the absence of any commercial or financial relationships that could be construed as a potential conflict of interest. 


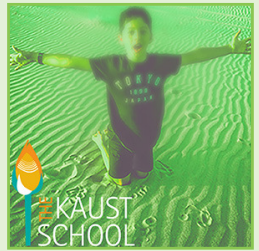

COPYRIGHT @ 2021 Barreto, Herrera and Aranda. This is an open-access article distributed under the terms of the Creative Commons Attribution License (CC BY). The use, distribution or reproduction in other forums is permitted, provided the original author(s) and the copyright owner(s) are credited and that the original publication in this journal is cited, in accordance with accepted academic practice. No use, distribution or reproduction is permitted which does not comply with these terms.

\section{YOUNG REVIEWER}

\section{FABIAN, AGE: 14}

Fabián is a world traveling, 14 year old, ninth grade polyglot who loves the ocean and being creative. His hobbies are: mountain biking, lego, inventing, acting, and reading, but especially reading. He loves being a part of the Frontiers for Young Minds program and looks forward to next year!

\section{AUTHORS}

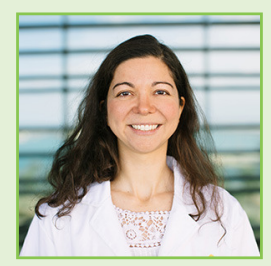

\section{MARCELLE M. BARRETO}

I was always interested in nature as a child, so choosing environmental sciences as a career was not a surprise to anyone. Now I am a Ph.D. student, focusing on coral reefs. I am exploring new strategies to try to save coral reefs from current threats, such as climate change. When I am not at work, you can usually find me traveling, dancing, working on handcraft projects and playing my ukulele. *marcelle.munizbarreto@kaust.edu.sa

\section{MARCELA HERRERA}

I am a marine scientist who wants to understand how different organisms adapt to the changing conditions of our oceans. I love to travel, explore the underwater world, and try new foods.

\section{MANUEL ARANDA}

I am a Biology Professor at the King Abdullah University of Science and Technology in Saudi Arabia. I study why corals are so sensitive to climate and how we might be able to help them. In my free time I like to cook and to play Playstation with my son. 